\title{
RANCANG BANGUN MUSIK ANGKLUNG MODEL ELECTONE ORGAN PERPADUAN KOMBINASI BAS, HARMONI, DAN MELODI
}

\author{
A. M. Susilo Pradoko, Fransisca Xaveria Diah, dan H. T. Silaen \\ FBS, Universitas Negeri Yogyakarta \\ E-mail: susilopradoko@yahoo.com
}

\begin{abstract}
Abstrak
Penelitian ini bertujuan untuk mengembangkan instrumen musik angklung. Seorang pemain musik angklung biasanya hanya memainkan satu nada dari bagian melodi saja. Penelitian ini mengembangkan teknik bermain angklung sehingga seorang pemain angklung mampu memainkan melodi, harmoni, iringan, dan bas sekaligus. Seorang pemain secara simultan mampu memainkan sebuah lagu beserta iringan musiknya serta nada-nada bas yang bersesuaian. Metode dalam penelitian ini menggunakan metode Research \& Development. Peneliti merancang konstruksi untuk seperangkat melodi, iringan harmoni, serta iringan bas. Proses penelitian dilalui dengan merancang produk, memvalidasi rancangan, merevisi rancangan, proses pembuatan perangkat angklung melodi, bas, dan harmoni. Revisi Produk dilakukan dengan dengan penyempurnaan teknik, uji coba pemakaian, dan akhirnya penggunaan dalam pementasan saat presentasi hasil penelitian. Hasil rancangan diwujudkan dalam pembuatan angklung model electone dan setelah menjadi wujud rangkaian melodi dimainkan tangan kanan dengan sistem tuts piano, bas angklung dimainkan dengan kaki, harmoni akor dimainkan tangan kiri. Produk kesatuan angklung ini disebut dengan angklung garbha swara. Seorang pemain mampu menghadirkan sebuah lagu dengan iringan harmoni serta pilihan nada-nada bas yang berkesesuaian dengan lagu tersebut.
\end{abstract}

Kata kunci: angklung, model electone, kombinasi, garbha swara

\section{DEVELOPING MODEL OF ANGKLUNG ELECTONE ORGAN: THE COMBINATION OF BASS, HARMONY, AND MELODY}

\begin{abstract}
This research aims to develop angklung musical instrument. A player of angklung usually only plays one note of the melody parts only. This study developed a technique of playing the angklung so that a player is able to play the melody, harmony, and bass accompaniment simultaneously. A simultaneous player is able to play a song with musical accompaniment and bass tones corresponding. The method in this research is Research \& Development. The researchers designed the construction of a set of melody, harmony accompaniment, and bass accompaniment. The research process is done by designing products, validating the draft, revising the draft, manufacturing process of the melodic angklung device, bass, and harmony. Revising the product is done by perfecting the technique, testing the product, and using the product on a stage performance. The results of the draft is realized by manufacturing a model of angklung electone organ. After the model is done, a set of harmony is played using the right hand with piano keys system, angklung bass is played using the feet, harmony chords are played using the left hand. This unitary product is called angklung garbha swara. A player is able to present a song to the accompaniment of harmony as well as a large selection of bass tones that correspond with the song.
\end{abstract}

Keywords: angklung, electone model, combination, garbha swara 


\section{PENDAHULUAN}

Angklung telah ditetapkan sebagai warisan budaya tak benda (Intangible, Cultural Heritage of Humanity) oleh Organisasi Pendidikan, Ilmu Pengetahuan, dan Kebudayaan (UNESCO) Peserikatan Bangsa-Bangsa (PBB) pada bulan November 2010. Sementara itu Duta Besar Indonesia untuk UNESCO menyatakan bahwa dalam waktu empat tahun bila Indonesia tidak bisa melestarikan serta mengembangkannya maka pengakuan warisan budaya tak benda tersebut bisa dicabut (Kompas, 20 Januari 2011). Perguruan Tinggi memiliki tugas pengembangan ilmu khususnya angklung ini, sebab selama ini angklung belum banyak dikaji secara akademik melalui penelitian namun hanya dilestarikan dan dikembangkan melalui para pengrajin angklung. Pengrajin angklung yang masih rutin berproduksi di Indonesia ini hanya dua kelompok yaitu Serambu Sumitro di Yogyakarta dan Saung Angklung Ujo. Pengembangan dalam bidang ilmu dan teknologi angklung tidak cukup hanya diserahkan pada dua sentra pengrajin tersebut karena keduanya tidak memiliki tradisi metodologi penelitian ilmiah. Andil Perguruan Tinggi dalam pengembangan angklung sangat perlu agar kurun tiga tahun lagi setelah diamati PBB tidak dijatuhkan sanksi pencabutan warisan budaya tak benda tersebut (Pradoko, 2014:1).

Indonesia miskin tenaga ahli yang memiliki kemampuan melakukan metode penelitian ilmiah tentang etnomusikologi angklung. Hal itu dikhawatirkan akan mempengaruhi pengembangan angklung dan statusnya sebagai warisan budaya tak benda dari Indonesia. Husein Hendriyana, Kepala Bidang Penelitian dan Pengabdian Masyarakat STSI Bandung. menyatakan sebagai berikut: "Para pakar atau orang yang paham tentang angklung mungkin banyak. Tetapi yang mengerti metodologi penelitian ilmiah yang terstruktur saya rasa belum ada. Hal itu sangat ironis mengingat Indonesia merupakan negara asal angklung" (Kompas, 9 Februari 2011:12). Universitas Negeri Yogyakarta dapat merupakan salah satu pusat pengembangan akademik dalam bidang musik angklung karena secara nyata memang masih langka pakar metodologi ilmiah tentang angklung.
Angklung telah ditetapkan pula sebagai alat pendidikan musik sejak tanggal 23 Agustus 1968 melalui Keputusan Menteri Kebudayaan No.082/1968 tentang penetapan angklung sebagai alat pendidikan musik namun sampai saat ini pengembangan maupun penerapannya di sekolah-sekolah masih sangat minim (Winitasasmita, dkk., 1978:5). Perhatian dunia Perguruan Tinggi memang masih sangat kurang hal ini disebabkan pula masih sangat jarang Perguruan Tinggi yang memberikan materi mata kuliah angklung sehingga aspek metodologis dan praksisnya dalam pertunjukan musik juga sulit berkembang. Selain itu peralatan angklung ditata memanjang dengan bentuk yang relatif besar-besar untuk satu nada, sehingga memakan banyak tempat dan memerlukan kesulitan tersendiri dalam penyimpanan angklung di ruangan/kelas. Guru musik yang memiliki kemampuan teoritis musik angklung maupun metodologis dalam menyampaikan pembelajaran musik hingga pementasan juga sangat sedikit, karena pencantuman angklung sebagai materi mata kuliah baru dilakukan oleh UPI dan UNY, sebagai LPTK pendidik guru di sekolah-sekolah. Pembelajaran angklung dengan menggabungkan orchestra telah dirintis sejak tahun 1996 dalam Mata Kuliah Musik Nusantara dan Mata Kuliah Etnomusikologi. Pengembangan angklung sangat minim di Indonesia baik dari sisi metodologi musikal, pembelajaran, maupun pengembangan peralatan musik angklung. Untuk itu Pendidikan Seni Musik FBS UNY terbeban untuk pengembangan musik angklung yang telah diakui UNESCO sebagai Intangible, Cultural Heritage of Humanity tersebut.

Angklung yang diajarkan selama ini masih berpola pada permainan satu nada dibunyikan oleh seorang pemain. Permainan model ini membutuhkan banyak orang untuk menghasilkan bunyi harmoni yang terpadu. Permainan model angklung seperti ini setidaknya memerlukan sekitar 25 orang pemain agar suaranya menjadi harmonis berdasarkan susunan nada-nada dan pemilihan teknik akor yang digunakan.

Angklung digunakan untuk mengiringi melodi yang dihasilkan dari permainan model 
angklung satu-satu nada yang telah diuraikan sebelumnya. Angklung ini merupakan angklung akor, dalam satu angklung ada 3 tabung yang merupakan bunyi-bunyi akor nada-nadanya, sehingga mampu untuk mengiringi menjadi lebih indah, salah satu diantaranya misalnya angklung akompanyemen akor $\mathrm{C}$.

Teknik permainan angklung secara tradisional membutuhkan setidaknya 15 orang. Sekitar 9 orang memainkan angklung melodi, 4 orang memainkan angklung akompanyemen, dan satu atau dua orang memainkan bas bambu. Permainan ini biasanya saat ini dimainkan di tingkat SD atau SMP. Teknik permainan angklung yang lebih kompleks perpaduan nadanadanya biasanya dimainkan sekitar 35 orang pemain untuk dapat memainkan komposisi paduan suara, angklung, dan angklung bas.

Dengan adanya pengakuan dari UNESCO terhadap angklung sebagai warisan budaya dunia, hal ini mengandung konsekuensi untuk menjaga kelestarian sekaligus mengembangkan angklung baik secara tangible maupun intangible. Aspek permainan teknis yang membutuhkan puluhan orang untuk dapat memainkan angklung dengan komposisi yang lengkap yaitu perpaduan harmoni, melodi, dan irama penguat bas membuat peneliti berupaya menjawab tantangan pengembangan alat musik angklung, yaitu bagaimana dengan satu orang pemain dapat sekaligus memainkan aspek melodi, akor harmoni, dan bas yang sesuai dalam satu set angklung (angklung electone).

\section{METODE}

Metode penelitian dan pengembangan (research and development) merupakan metode penelitian yang digunakan untuk menghasilkan produk dan menguji produk tersebut. Metode ini telah banyak digunakan pada bidang-bidang ilmu alam dan teknik. Hampir semua produk teknologi seperti alat-alat elektronik, kendaraan bermotor, pesawat terbang, kapal, senjata, obatobatan, alat-alat kedokteran, bangunan gedung bertingkat, dan alat-alat rumah tangga yang modern diproduksi dan dikembangkan melalui penelitian dan pengembangan. Walaupun demikian, metode penelitian dan pengembangan dapat juga digunakan dalam ilmu sosial (Sugiyono, 2009:297).

Pada penelitian rancang bangun angklung electone ini akan diterapkan metode penelitian research and development seperti yang telah diungkapkan oleh Sugiyono (2009) dalam buku Metode Penelitian Kuantitatif Kualitatif dan R\&D dengan sedikit modifikasi penelitian penciptaan seni Susilo Pradoko, dkk. tahun 2014. Berikut ini akan dipaparkan bagan langkah-langkah metode R\&D Sugiyono (2009) dengan sedikit modifikasi dapat dilihat pada gambar 1 dan gambar 2.

Pola penerapan proses kerja mewujudkan konsep langkah-langkah bagan adalah: 1) Masalah dan potensi, konsekuensi angklung ditetapkan sebagai warisan budaya dunia adalah melestarikan sekaligus mengembangkan permainan dan teknik alat musik angklung. Bahan baku bambu sangat banyak di Indonesia ini, hampir setiap desa terdapat tanaman bambu. 2) Pengumpulan data: model-model angklung dengan teknik disentuh, dipelajari. Teknik ini digunakan di pengamen angklung Malioboro, teknik angklung "Toel” Mang Ujo. 3) Pembuatan desain untuk set melodi, akor, dan bas. 4) Validasi desain angklung model electone organ dengan perbaikan teknik yang tepat sesuai saran teknisi yang lebih ahli. 5) Revisi desain sesuai saran agar lebih praktis dan indah serta mudah dikonstruksi dan dimainkan. 6) Proses penciptaan, proses pembuatan angklung electone dengan membuat set melodi, set akompanyemen iringan akor dan bas angklung yang terletak di bawah angklung melodi. 7) Perbaikan-perbaikan teknis untuk penyesuaian posisi antara set melodi, harmoni bas, dan finishing produk. 8) Uji coba pemakaian permainan angklung electone. 9) Pentas Angklung Electone di hadapan publik/penonton. 10) Proses pembuatan HAKI. 11) Produksi angklung electone dan publikasi masa.

\section{HASIL DAN PEMBAHASAN \\ Model Angklung SATB SP}

Angklung electone yang akan diproduksi mengkombinasikan gagasan pembuatan angklung SATB SP yang dibuat oleh A. M. 


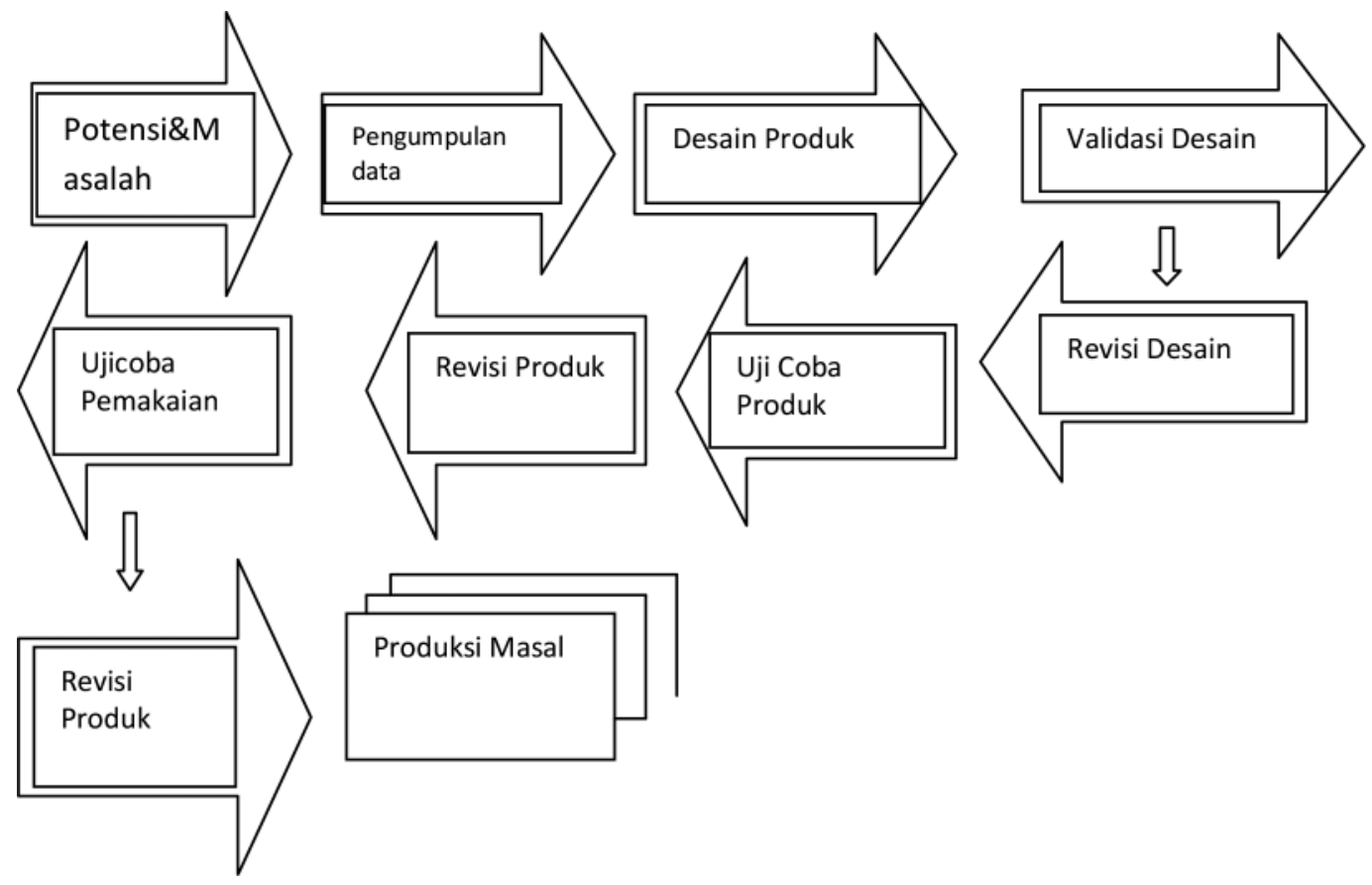

Gambar 1. Langkah-langkah R\&D

(Sumber: Sugiyono, 2009:298)

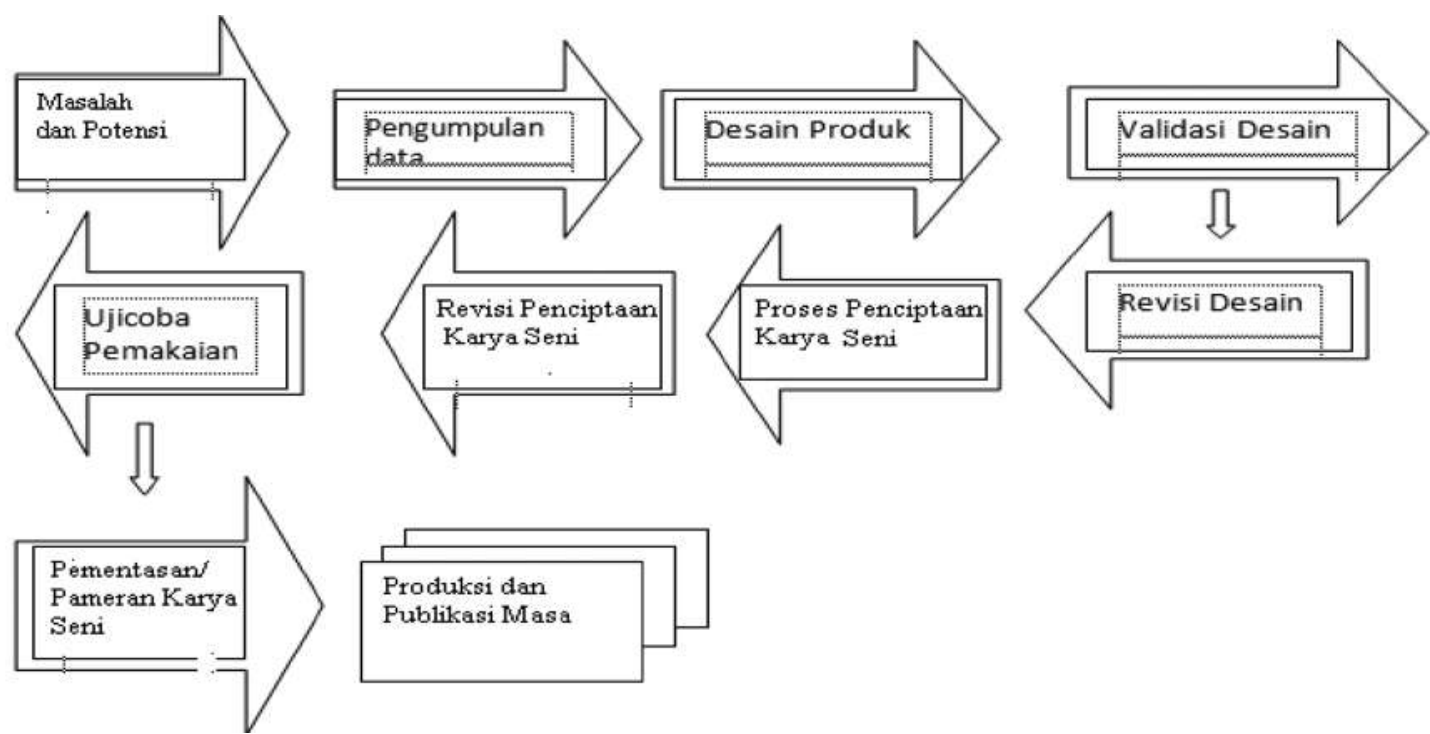

Gambar 2. Langkah-langkah R\&D Modifikasi Karya Cipta Seni (Sumber: Rancang Bangun Musik Angklung Model SATB, Pradoko, dkk., 2014:11)

Susilo Pradoko, dkk., terutama penggunaan sistem tuts-tuts, atau bilah-bilah nada untuk melodi sopran seperti teknik permainan piano. Sistem bilah nada tersebut adalah sebagai berikut.

\section{Rancangan Angklung Sistem Piano}

Set angklung seperti yang telah dirancang dalam sistem harmoni 4 suara (SATB) kemudian akan dikembangkan lagi dengan model tuts piano. Model tuts dibuat dengan cara:

1. Membuat bilah-bilah papan tuts sebagai sarana jari-tangan penekan angklung 

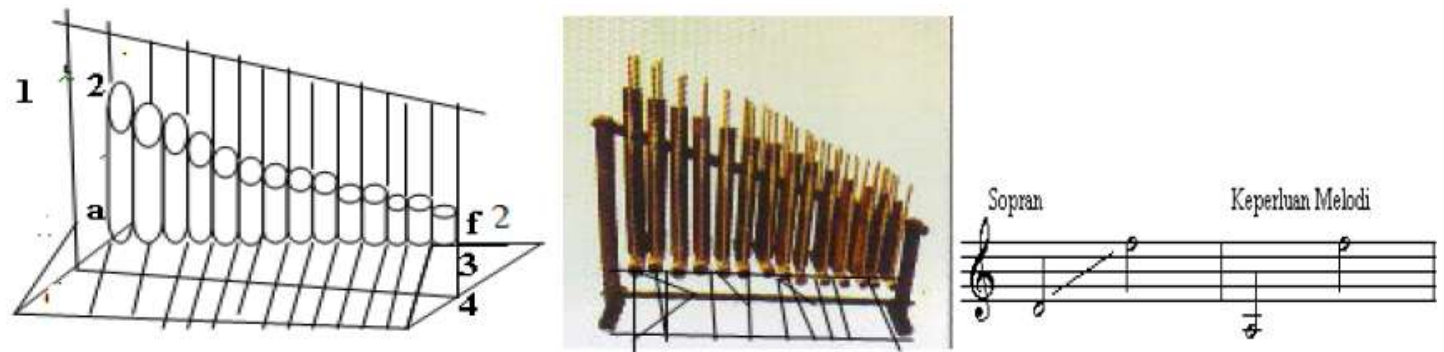

Gambar 3. Sketsa Angklung

Keterangan:

1. Kerangka angklung

2. Tabung-tabung angklung nada-nada wilayah melodi sopran:

terdiri dari nada-nada dari a s/d f2 yaitu nada-nada: a, ais, b, c1, cis1, d1, dis1, e1, f1, fis1, g1, gis 1, a, ais1, b1, c2, cis2, d2, dis2, e2, f2. Terdiri dari 21 tabung nada dan masing-masing nada ada dua tabung melodi agar ada penguat suara nada pokok; sehingga ada 42 tabung nada untuk angklung sopran

3. Pantulan karet kanan

4. Pantulan karet kiri

2. Membuat siku memanjang sebagai perluasan pemukul tuts

3. Membuat tuts dorong guna mendorong karet yang ada pada bilah-bilah melodi angklung

Selengkapnya bisa melihat gambar berikut:

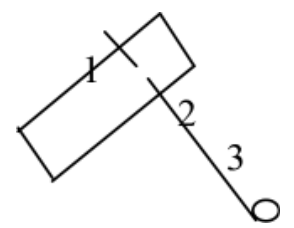

Gambar 4. Sketsa Karet Penghubung Angklung

Selanjutnya, digabungkan antara angklung pantulan karet set angklung sopran, yang diperlukan untuk melodi dengan pemantik tuts angklung seperti diuraikan dan telah digambarkan tersebut.

\section{Angklung Electone Kombinasi Melodi, Harmoni, dan Bas}

Rancang bangun electone kombinasi melodi harmoni dan bas dibuat dengan memadukan seperangkat set angklung melodi, angklung

akor, dan bas bambu. Seperangkat angklung melodi akan dirakit dengan posisi di depan seorang yang memainkan dengan tangan kiri. Angklung akor harmoni akan dibuat dengan posisi di sebelah samping kiri pemain angklung electone tersebut, cara memainkannya dengan menggunakan tangan kiri. Bas terbuat dari bambu akan dibuat menyatu dengan angklung melodi, teknik memainkan dengan menginjakkan kaki, injakkan kaki tersebut diteruskan dengan papan dan memukul bas bambu tersebut. Selengkapnya desain gambarnya sebagai berikut.

\section{Proses Pembuatan dan Hasil Produk Angklung Electone}

\section{Proses Pembuatan}

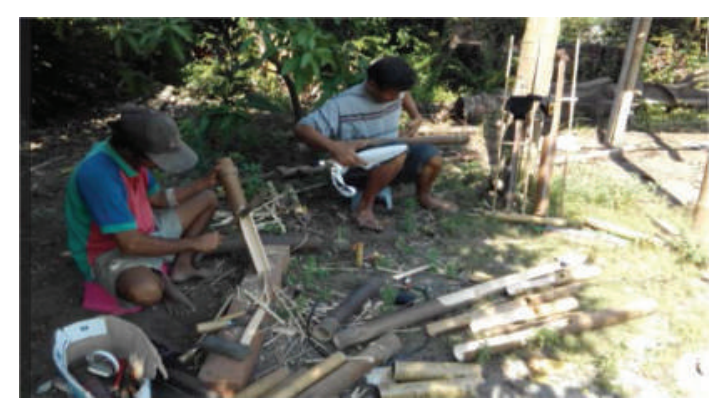

Gambar 6. Pengrajin Membuat Dasar Angklung Electone 


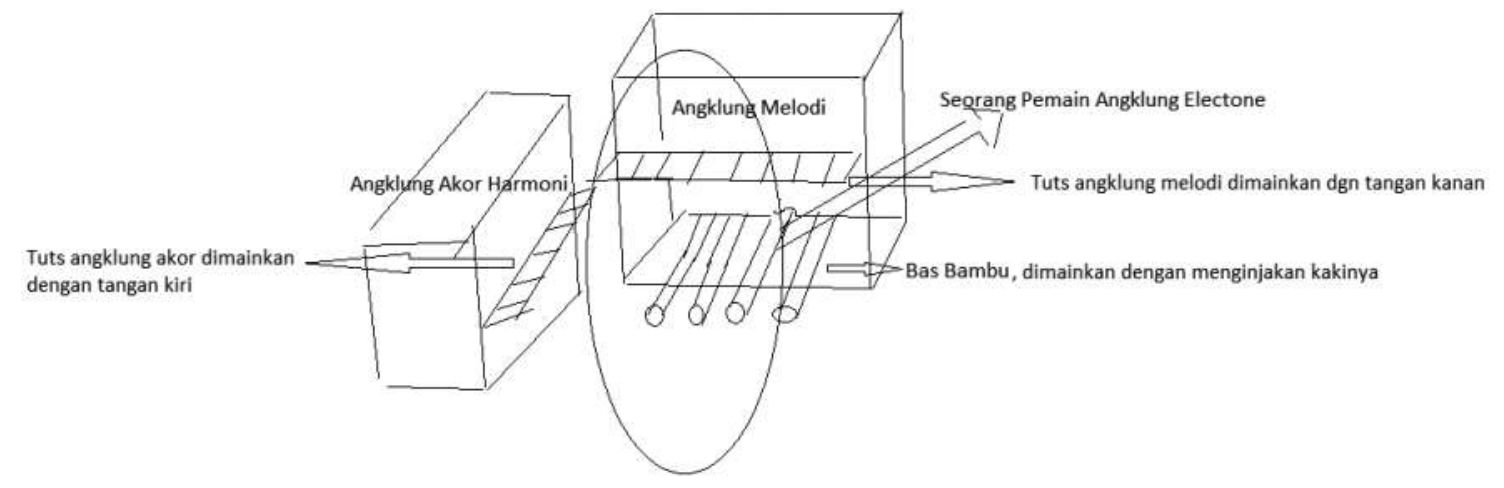

Gambar 5. Sketsa Angklung Electone

\section{Hasil Produk Rancang Bangun Angklung Electone}

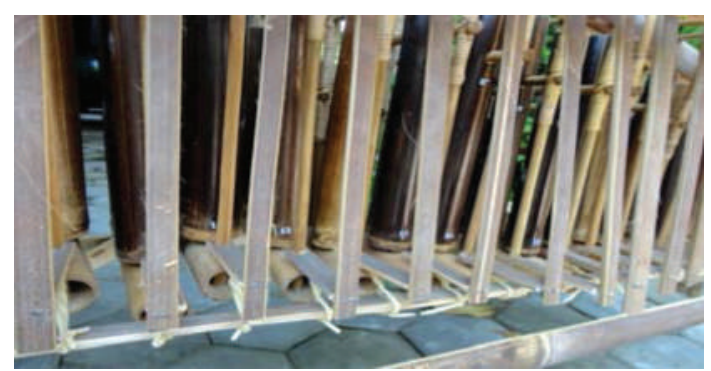

Gambar 7. Bas Angklung

Angklung 3 set yaitu set melodi dan bas, harmoni, dan filler melodi kecil yang selanjutnya disebut angklung garbha swara menjalani uji coba pemakaian. Setelah proses uji coba, selanjutnya pembuatan mengganti karet gelang sebagai per diganti dengan tali plastik pengikat pengepakan barang dengan bentuk setengah lingkaran agar dapat menarik dan memantulkan kembali angklung yang digoyang melalui tarikan benang, dan ternyata reaksinya lebih cepat. Reaksi spontan ini bagaikan kendaraan yang berkualitas baik, yaitu reaksi antara perbesaran gas dan laju kendaraan dapat spontan. Penggunaan tali plastik pengepakan barang ini lebih spontan daripada dengan karet gelang, sehingga tidak mengganggu durasi dalam permainan musik.

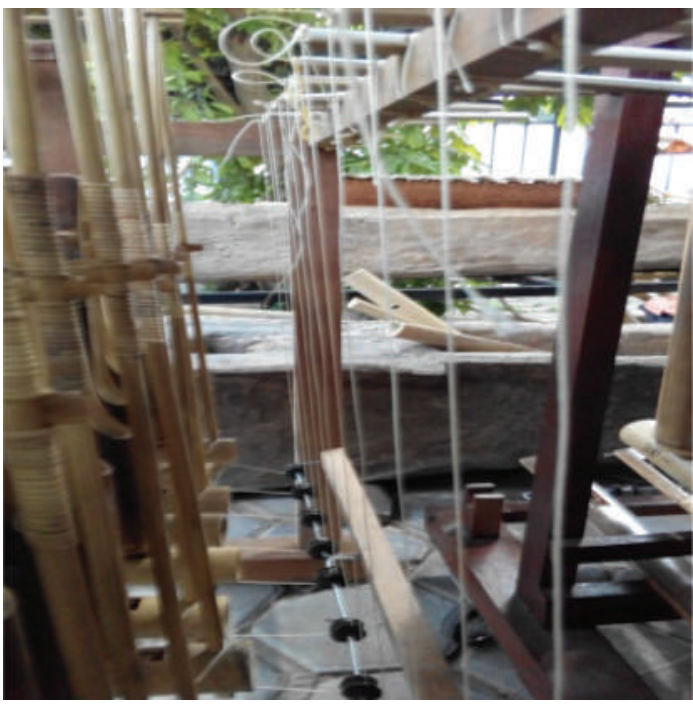

Gambar 8. Bentuk Karet Penghubung pada Bas Angklung

Berikut ini foto penggunaan tali plastik yang berfungsi sebagai per penggerak angklung.

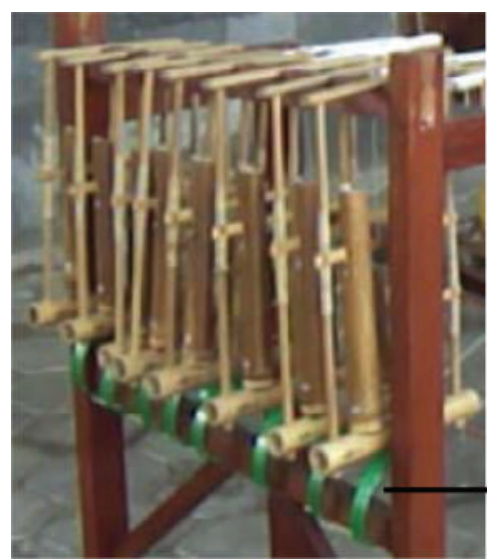

Gambar 9. Tali Plastik Berfungsi sebagai Per Pantul 
Hasil revisi produk pembenahan terakhir mulai dari pembenahan perpanjangan tuts dari bilah bambu menjadi benang dengan sekoci putar, pembenahan karet per gelang diganti dengan tali plastik untuk pengikat barang dengan model setengah lingkaran meliputi perangkat angklung melodi dan bas, perangkat akompanyemen akor, dan perangkat perluasan melodi kecil filler menjadi sebagai berikut.

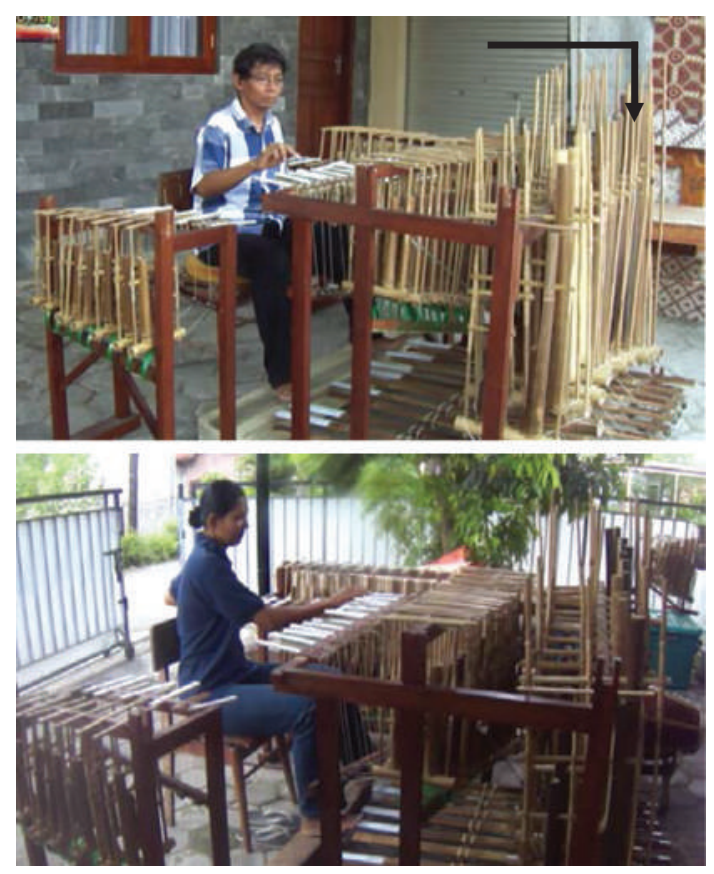

Gambar 10. Hasil Produk Rancang Bangun Angklung Electone sedang dimainkan Tim Penelitian

\section{KESIMPULAN}

Seperangkat angklung melodi dirangkai dengan sisitem tuts-tuts piano sehingga orang mudah dalam memainkan, tanpa harus menggoyang satu angklung dengan dua tangan. Seorang pemain dapat melakukan permainan melodi sendiri. Teknik pembuatan angklungnya dengan perpanjangan tuts-tuts melalui tarikan benang menuju angklung melodi. Angklung melodi yang mendapat tarikan benang mampu bergerak kembali karena adanya plastik setengah lingkaran yang berfungsi sebagai per pengembali gerak saat benang ditarik tangan melalui tuts-tuts, papan nada.
Desain seluruh rangkaian dengan membuat tiga perangkat angklung, yaitu angklung melodi dan bas, perangkat angklung akompanyemen akor, dan seperangkat desain angklung perluasan melodi kecil dan sekaligus sebagai filler melodi. Desain dasar dari tiga perangkat angklung ini dengan menggunakan tuts-tuts penarik yang diteruskan dengan benang sehingga menarik angklung, angklung mampu kembali pada posisi semula karena ada plastik lingkaran yang berfungsi sebagai per pengembali tekanan tarikan benang.

Satu set seperangkat angklung melodi dan bas dirangkai dengan sistem tuts-tuts yang digerakkan oleh tangan dan kaki. Saat tangan dan kaki menekan tuts maka tuts menarik benang, dan benang kemudian meneruskan tarikan melalui lingkar cincin sekoci dan akhirnya menggerakan angklung melodi dan bas.

Teknik menempatkan tiga perangkat angklung yang terdiri dari melodi dan bas, akompanyemen iringan, serta melodi kecil dengan ditata setengah lingkaran mengelilingi seorang pemain angklung ini membuat pemain mampu merangkum dan mengkombinasikan permainan melodi, harmoni, filler melodi, serta bas yang saling berkesesuaian dan mendukung sesuai dengan lagunya. Kombinasi melingkar tiga perangkat angklung ini disebut sebagai angklung garbha swara.

\section{DAFTAR PUSTAKA}

Annabel, Angela R. 1985. "Javanese Angklung in The Auckland Institute and Museum". Records of The Auckland Institute and Museum. Vol. 22, pp. 31-40. http://www. jstor.org/stable/42906347.

Kawakami, Genichi. 1975. Arranging Popular Music. Tokyo: Yamaha Music Foundation.

Kompas. 2011. "Pengakuan Warisan Budaya Bisa Dicabut". Kompas, tanggal 20 Januari 2011.

Kompas. 2011. "Tenaga Ahli Angklung Masih Sangat Terbatas". Kompas, tanggal 9 Februari 2011. 
Korsakov, Nikolay Rimsky. 1964. Principles of Orchetration. New York: Dover Publication.

Perris, Arnold B. 1971. "The Rebirth of The Javanese Angklung”. Ethnomusicology, Vol. 15, No. 3, pp. 403-407. http://www. jstor.org/stable/85064.

Pradoko, A.M. Susilo, dkk. 2014. "Rancang Bangun Musik Angklung Model SATB, Dasar Aransemen Model Orchestra”. Laporan Hasil Penciptaan Karya Seni, Fakultas Bahasa dan Seni Universitas Negeri Yogyakarta.

Pratiwi, Annisa. 2013. "Pelestarian Angklung Sebagai Warisan Budaya Takbenda dalam Pariwisata berkelanjutan di Saung Angklung Udjo, Bandung". Tesis Program Pascasarjana Universitas Udayana.

Rochmad. 2012. "Desain Model Pengembangan Perangkat Pembelajaran Matematika". Kreano. Jurusan Matematika MIPA UNNES.

Supriyadi. 2006. "Calung dan Cara Pembuatannya". Selonding Vol. 4, No. 2, Jurusan Etnomusikologi ISI Yogyakarta.

Winisasmita, Moh. Hidayat, dan Budiaman. 1978. Angklung Petunjuk Praktis. Jakarta: Balai Pustaka. 